Удк631.445.2:631.415.

doi: $10.31140 /$ j.vestnikib.2016.4(198).3

\title{
ВОДОРАСТВОРИМЫЕ ОРГАНИЧЕСКИЕ СОЕДИНЕНИЯ ТОРФЯНЫХ ПОЧВ СЕВЕРНОЙ ЧАСТИ БОЛЬШЕЗЕМЕЛЬСКОЙ ТУНДРЫ
}

\author{
Е.В. Шамрикова, С.В. Денева, О.С. Кубик, В.В. Пунегов, Е.В. Кызъюрова, О.М. Зуева \\ Федеральное государственное бюджетное учреждение науки \\ Институт биологии Коми научного центра Уральского отделения РАН, Сыктывкар \\ E-mail: shamrik@ib.komisc.ru
}

\begin{abstract}
Аннотация. Изучены растворимые органические соединения торфяных почв побережья Баренцева моря. Определено девять кислот и семь углеводов. Установлено, что содержание общего углерода органических соединений, экстрагируемого водой, составляет 0.2-0.5 г/дм ${ }^{3}$, низкомолекулярных углеводов 1-24, кислот - 6 мг/дм³. Массовая доля углерода идентифицированных соединений составляет менее $4 \%$ от общего углерода органических соединений вытяжек.
\end{abstract}

Ключевые слова: торфяные почвы, Арктика, водные и КСІ-вытяжки из почв, низкомолекулярные органические кислоты и углеводы

\section{Введение}

Российская Федерация имеет самую длинную в мире береговую линию. Исследования почвоведов в прибрежных зонах арктических морей единичны и их результаты не дают полного представления о генезисе и свойствах почв. В отношении растворимых органических соединений данные почвы не исследованы в принципе. Однако именно береговые зоны Арктики в первую очередь оказываются ареной экосистемных конфликтов, связанных с трансформацией климата, продвижением в высокие широты бореальных видов и усиливающимся антропогенным влиянием на природные комплексы.

Фактором, определяющим образование почв прибрежных территорий, является регулярное подтопление солеными водами. Это обстоятельство определяет изменение миграционной способности органических соединений, так как степень их экстракции зависит от концентрации электролита. Изучение подвижности органических соединений почв в зависимости от ионной силы раствора актуально и для выявления источников потенциальной кислотности почв.

Сведения о составе низкомолекулярных органических соединений в водных и солевых вытяжках почв прибрежных арктических территорий отсутствуют. Основной массив данных касается почв, развивающихся в условиях таежного ( $\mathrm{Wu}$, 2010; Артемкина, 2011; Clemente, 2011; Liquid..., 2011; Исследование..., 2012; Водорастворимые..., 2013 и др.), в меньшей степени - тундрового почвообразования (Водорастворимые..., 2013, 2015). Среди ведущих методов анализа индивидуальных компонентов почв - ВЭЖХ, капиллярный электрофорез, а также газовая хроматография и хромато-масс-спектрометрия (ГХ/MC) с предварительной дериватизацией нативных соединений. В отношении состава и содержания тех или иных компонентов данные противоречивы. Неоднозначность результатов анализа растворов из почв определяют различные факторы, среди них метод определения и пробоподготовка объектов исследования (Strobel, 2001; Качественный..., 2011), способ получения раствора (Караванова, 2009; Шамрикова, 2011), а также высокое простран- ственно-временное варьирование данной характеристики ( $\mathrm{Wu}, 2010)$.

Целью работы явилось определение состава растворимых органических соединений торфяных почв побережья Баренцева моря.

\section{Материалы и методы}

Район исследований располагается в прибрежной части Хайпудырской губы Баренцева моря. Территория входит в подзону северных гипоарктических тундр (Юрцев, 1966). В качестве объектов исследования выбраны почвы тундровых экосистем, широко распространенные в данной подзоне: торфяная олиготрофная мерзлотная и торфяно-глеезем криогенно-ожелезненный мерзлотный (Классификация..., 2004). Согласно Международной Реферативной базе почвенных ресурсов (World Reference..., 2014), почвы диагностированы как Cryic Fibric Histosols Dystric и Histic Reductaquic Cryosol Thixotropic. Точки отбора образцов: $68^{\circ} 20^{\prime} 05.7^{\prime \prime}$ с.ш., $59^{\circ} 33^{\prime} 21.9^{\prime \prime}$ в.д. и $68^{\circ} 16^{\prime}$ $58.9^{\prime \prime}$ с.ш., $59^{\circ} 54^{\prime} 49.5^{\prime \prime}$ в.д. соответственно, высота $-8 \mathrm{м}$ над уровнем моря.

Химический анализ почв выполняли общепринятыми методами (табл. 1). Массовую долю общего углерода органических соединений в твердой фазе почв определяли на CHNS-элементном анализаторе EA 1110 (Carlo Erba, Италия). Элементный состав объектов определяли методом атомно-эмиссионной спектрометрии с индуктивно связанной плазмой SPECTRO ARCOS. Разложение проб органогенных горизонтов почв выполняли методом микроволнового вскрытия с использованием СВЧ-минерализатора «Минотавр- 2 » (Россия, $\mathrm{OOO}$ «Люмэкс»).

Вытяжки из почв готовили в соотношении 1:25. Массовую концентрацию общего углерода органических соединений водных $\rho\left(\mathrm{C}_{\mathrm{OC}_{-} \mathrm{H}_{\mathrm{O}}}\right)$ и солевых $\rho\left(\mathrm{C}_{\mathrm{OC}-\mathrm{k} l}\right)$ вытяжек определяли методом высокотемпературного каталитического окисления на анализаторе общего углерода TOC $\mathrm{V}_{\mathrm{CPH}}$ (ГОСТ..., 2009) по разности общего содержания углерода и углерода неорганических соединений. Низкомолекулярные органические соединения в вытяжках идентифицировали методами газовой хроматографии и хромато-масс-спектрометрии, 
Характеристика химических свойств почв

\begin{tabular}{|c|c|c|c|c|c|c|c|c|c|c|c|}
\hline \multirow{3}{*}{ Горизонт } & \multirow{3}{*}{$\mathrm{pH}_{\mathrm{H} 2 \mathrm{O}}$} & \multirow{3}{*}{$\mathrm{pH}_{\mathrm{KCl}}$} & \multicolumn{4}{|c|}{ Обменные катионы } & \multicolumn{5}{|c|}{ Валовый состав } \\
\hline & & & $\mathrm{Ca}^{2+}$ & $\mathrm{Mg}^{2+}$ & $\mathrm{Al}^{3+}$ & $\mathrm{H}^{+}$ & $\mathrm{C}_{\text {общ }}{ }^{*}$ & $\mathrm{Ca}$ & $\mathrm{Mg}$ & $\mathrm{Al}$ & $\mathrm{Fe}$ \\
\hline & & & \multicolumn{4}{|c|}{$n\left(1 / z X^{2+}\right) / m^{* *}$, ммоль/кг } & \multicolumn{5}{|c|}{$\%$} \\
\hline \multicolumn{12}{|c|}{ Торфяная эутрофная мерзлотная } \\
\hline $\mathrm{O}$ & 3.87 & 2.80 & 73 & 89 & 38.3 & 55.0 & 43.4 & 0.18 & 0.15 & 0.15 & 0.17 \\
\hline $\mathrm{T} 1$ & 3.96 & 2.73 & 111 & 110 & 43.3 & 36.7 & 44.7 & 0.19 & 0.12 & 0.11 & 0.13 \\
\hline $\mathrm{T} 2$ & 3.98 & 2.91 & 73 & 43 & 58.3 & 20.0 & 44.4 & 0.20 & 0.07 & 0.23 & 1.50 \\
\hline $\mathrm{T}_{1}$ & 4.04 & 3.03 & 73 & 31 & 68.3 & 15.0 & 46.8 & 0.29 & 0.08 & 0.35 & 0.79 \\
\hline \multicolumn{12}{|c|}{ Торфяно-глеезем криогенно-ожелезненный мерзлотный } \\
\hline $\mathrm{O}$ & 3.80 & 2.84 & 61 & 55 & 47.8 & 38.9 & 40.3 & 0.20 & 0.11 & 0.18 & 0.17 \\
\hline $\mathrm{T} 1$ & 3.93 & 2.91 & 85 & 86 & 42.5 & 17.5 & 40.9 & 0.25 & 0.12 & 0.12 & 0.12 \\
\hline $\mathrm{T} 2$ & 4.43 & 3.51 & 100 & 71 & 80.0 & 15.0 & 31.0 & 0.28 & 0.16 & 0.83 & 1.40 \\
\hline $\mathrm{G}_{\text {сf тикс }}$ & 5.51 & 3.59 & 40 & 37 & 16.5 & 0.3 & 0.37 & - & - & - & - \\
\hline G1 & 5.48 & 3.97 & 18 & 37 & 5.7 & 0.2 & 0.39 & - & - & - & - \\
\hline G2 & 5.53 & 4.13 & 59 & 43 & 3.0 & 0.3 & 0.75 & - & - & - & - \\
\hline $\mathrm{G}_{\mid}$ & 5.92 & 4.40 & 24 & 15 & 0.7 & 0.3 & 0.46 & - & - & - & - \\
\hline
\end{tabular}

Примечание. ${ }^{*} \mathrm{C}_{\text {общ }}-$ общий углерод органических соединений, ${ }^{*} n\left(1 / \mathrm{z} \mathrm{X}^{z^{+}}\right) / m-$ количество вещества эквивалента в единице массы почвы.

относительная погрешность измерения составляет $\pm \delta \leq 3 \%$ (Исследование водных..., 2012).

Исследования проводили в Центре коллективного пользования «Хроматография», действующем на базе Института биологии Коми НЦ УрО $\mathrm{PAH}$, а также в экоаналитической лаборатории, отделах почвоведения и Ботанический сад.

\section{Обсуждение результатов}

Изучаемые объекты характеризуются высокой кислотностью $\left(\mathrm{pH}_{\mathrm{H}_{2} \mathrm{O}} 3.8-4.4, \mathrm{pH}_{\mathrm{KCl}} 2.7-3.5\right)$. Отношение активностей протонов в вытяжках из образцов почв, рассчитанных по әкспериментальным значениям $\mathrm{pH}$, составляет $\frac{a\left(\mathrm{H}^{+}\right)_{\mathrm{KCl}}}{a\left(\mathrm{H}^{+}\right)_{\mathrm{H} 2 \mathrm{O}}}=2-60$ (рис. 1).

Массовые концентрации общего углерода органических соединений водных вытяжек $\rho\left(\mathrm{C}_{\mathrm{OC}-\mathrm{H}_{\mathrm{O}}}\right)$ изучаемых объектов равны 0.2-0.5 г/дм ${ }^{3}$, что сопоставимо с ранее полученными данными по поч- вам тайги и южной гипоарктической тундры Республики Коми (Водорастворимые..., 2013, 2015; Влияние разнообразия..., 2014). При использовании солевого раствора отмечена тенденция к понижению содержания общего углерода KCl-вытяжек $\rho\left(\mathrm{C}_{\text {ос-ксl }}\right)$ относительно этого показателя в водных экстрактах, поскольку расхождение средних значений элемента двух выборок незначимо.

В среднем отношение $\frac{\rho\left(\mathrm{C}_{\mathrm{OC}-\mathrm{KCl}}\right)}{\rho\left(\mathrm{C}_{\mathrm{OC}-\mathrm{H} 2 \mathrm{O}}\right)}=0.9$ (рис. 1).

Среди индивидуальных соединений идентифицировано девять кислот и семь углеводов (табл. 2). Массовые концентрации этих компонентов в изучаемых объектах сопоставимы со значениями, полученными для почв тайги и южной тундры, и в основном невысокие. Массовая доля углерода идентифицированных соединений составляет менее $4 \%$ от общего углерода органических соединений вытяжек.
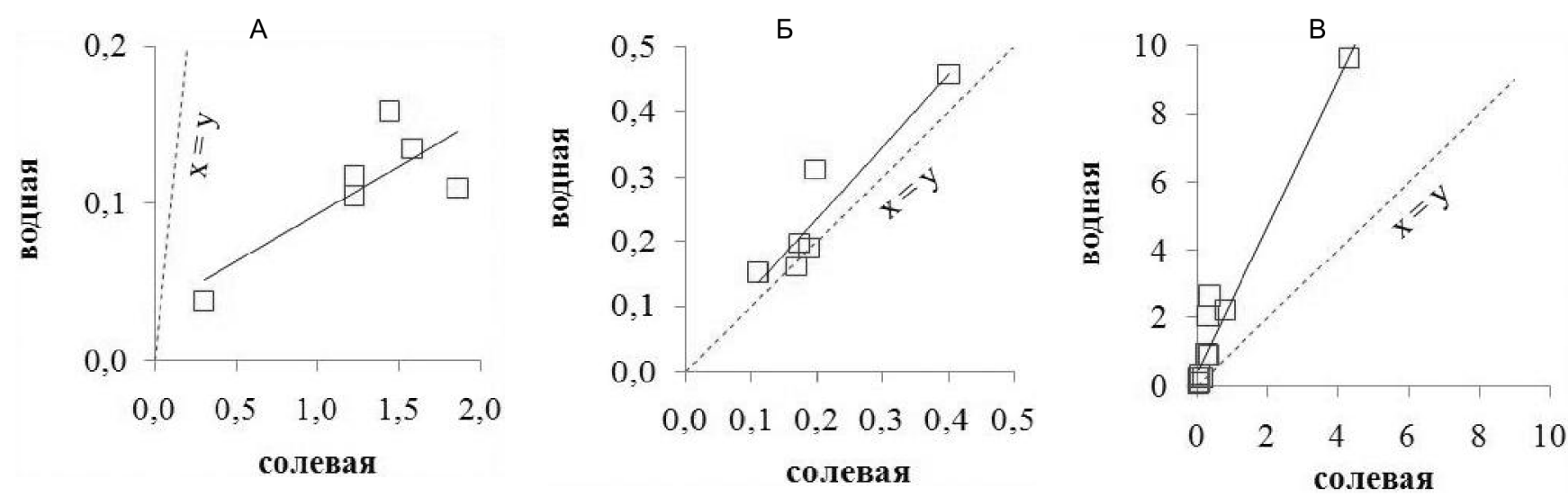

Рис. 1. Взаимосвязь концентраций компонента в солевой (ось абсцисс) и водной (ось ординат) вытяжках из почв: активность ионов водорода, ммоль/дм ${ }^{3}(\mathrm{~A})$; массовые концентрации общего углерода органических соединений,

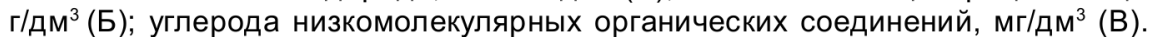


Таблица 2 Низкомолекулярные органические соединения почв, экстрагируемые водой и раствором хлорида калия

\begin{tabular}{l|l|l}
\hline Класс соединений & \multicolumn{1}{c}{ Водная вытяжка } & \multicolumn{1}{c}{ КСІ-вытяжка } \\
\hline Кислоты & 2-оксипропановая (молочная), 2-оксибутандикарбоновая (яблочная), 2,3,4-триоксибутановая, \\
2,3,4,5-тетраоксипентановая (рибоновая) & 2-оксиэтановая (2-оксиуксусная, гликолевая), 3-оксибутановая (3-окси- \\
& масляная), пентановая (валериановая), бутандионовая (янтарная), 2,3- \\
& диоксипропановая (глицериновая) \\
& Галактоза, арабиноза, рибоза, глюкоза, сахароза \\
Углеводы & Ксилопираноза, тураноза
\end{tabular}

Вне зависимости от генезиса почв суммарные массовые концентрации углеводов $\left(\rho_{\mathrm{y}}\right)$ и кислот $\left(\rho_{\mathrm{k}}\right)$ характеризуются тесной линейной связью: $\rho_{\mathrm{y}}=$ $2.39 \rho_{\mathrm{k}}+0.23(r=0.93, n=25)$. Более информативным показателем по сравнению с абсолютным значением является отношение массовых концентраций водорастворимых углеводов к кислотам $\left(k=\rho_{\mathrm{y}} / \rho_{\mathrm{\kappa}}\right)$. Все изучаемые в данной работе объекты можно объединить в одну группу с относительно высоким значением $k \geq 3.9$, в нее же попадают четыре образца многолетнемерзлой породы (Водорастворимые..., 2015). Возможно, рост $k$ связан с особенностями функционирования организмов в экстремальных условиях. По сведениям О.В. Зеленского (Зеленский, 1977), ткани растений Крайнего Севера содержат повышенное содержание углеводов, в первую очередь растворимых. Этот факт авторы связывают с физиологической адаптацией растений. Подстилки почв тайги и южной гипоарктической тундры, а также сезонно талый слой торфяных мерзлотных почв северной лесотундры характеризуются более низкими значениями данного показателя. В этой связи отношение массовых концентраций растворимых углеводов к кислотам, определенных методом ГХ/ MC, можно рассматривать как интегральный индекс, отражающий совокупность биохимических свойств организмов, обусловливающих их способность обитать на данной территории, а также условия, определяющие пути трансформации органических остатков. В наиболее жестких климатических условиях за счет накопления углеводов этот показатель выше, вероятно, в связи с адаптацией организмов к низкотемпературному стрессу.

Перечень низкомолекулярных кислот и углеводов в KCl-вытяжках всех объектов меньше по сравнению с водными вытяжками (табл. 1). В солевой раствор переходят те компоненты, содержание которых в водных вытяжках существенно. Так, органические кислоты, экстрагируемые раствором $\mathrm{KCl}$, в водных вытяжках составляют $42-94$, углеводы - более $90 \%$ от общего содержания соединений соответствующих классов. Отношение массовых концентраций углерода низкомолекулярных соединений $\rho\left(\mathrm{C}_{\mathrm{HC}}\right)$ в соответству ющих вытяжках $\frac{\rho\left(\mathrm{C}_{\mathrm{HC}-\mathrm{KCl}}\right)}{\rho\left(\mathrm{C}_{\mathrm{HC}-\mathrm{H} 2 \mathrm{O}}\right)}=0.5<1$, что ниже

отношения концентраций общего углерода органических соединений соответствующих вытяжек (рис. 1). Данный факт свидетельствует о том, что использование солевого раствора снижает раство- римость органических соединений по сравнению с водной экстракцией, однако снижение эффективности экстракции неодинаково.

Существенное уменьшение экстрагируемости низкомолекулярных органических веществ может быть связано с эффектом «высаливания». Механизм данного процесса заключается в том, что при введении электролита разрушаются гидратные оболочки вокруг молекул растворенного вещества, что уменьшает его сродство к воде гидрофильность. Система приходит в псевдоравновесное состояние (перенасыщенный раствор) и способствует выделению вещества из раствора, т.е. препятствует его растворению. Учитывая, что доля низкомолекулярных компонентов в составе общего углерода органических соединений невелика, существенного снижения общего углерода в солевых вытяжках из почв по сравнению с водными вытяжками не отмечено. Таким образом, вероятно, экстрагируемость относительно более высокомолекулярной фракции органического вещества изучаемых объектов в меньшей степени зависит от ионной силы раствора.

Далее оценили источники обменной кислотности изучаемых почв. Идентифицированные нами низкомолекулярные органические кислоты имеют $\mathrm{p} K_{\mathrm{a}}>3.8$ и не способны обеспечивать столь

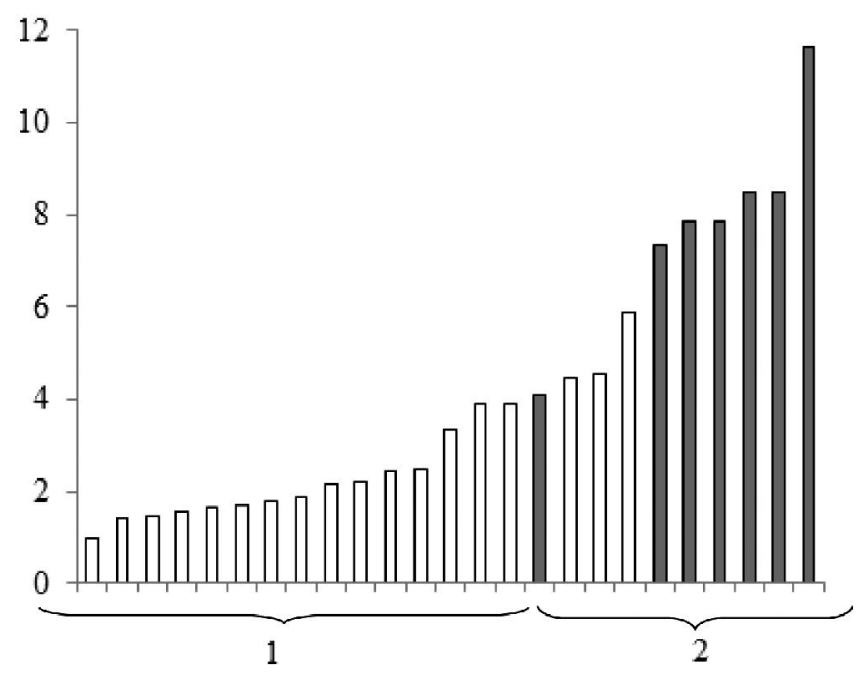

Рис. 2. Значения отношений массовых концентраций углеводов к кислотам, идентифицированным в почвах: 1 подстилки почв тайги, южной гипоарктической тундры, образцы сезонно-талых слоев торфяных мерзлотных почв северной лесотундры (Влияние разнообразия..., 2014; Водорастворимые..., 2015), 2 - исследуемые объекты (выделено цветом), образцы многолетнемерзлотной толщи торфяных мерзлотных почв северной лесотундры. 
низкие экспериментальные значения рН солевых вытяжек. Предполагаем, что протоны в солевом экстракте могут появиться в результате реакции обмена при вытеснении их из твердой фазы катионами калия. При этом источником таких протонов могут быть кислоты, характеризующиеся разной силой - от сильнокислотных до слабокислотных. Перейдя в раствор $\mathrm{H}^{+}$, вне зависимости от того, в состав какой по силе кислоты матрицы он входил, в жидкой фазе соответствует протону сильной соляной кислоты, диссоциирующей необратимо $\left(\mathrm{HCl} \rightarrow \mathrm{H}^{+}+\mathrm{Cl}^{-}\right)$и не имеющей константы кислотности. Таким образом, все протоны, перешедшие в KCl-вытяжки за счет реакции катионного обмена, - протоны сильной кислоты. Оценить вклад реакции катионного обмена в общую кислотность почв на данном этапе не представляется возможным.

Косвенным подтверждением этого факта является близость двух показателей. Нервый показатель - активность протонов, рассчитанная по экспериментальным значениям $\mathrm{pH}_{\mathrm{KCl}}$ и характеризующая наиболее сильнокислотные компоненты вытяжки, образовавшиеся при диссоциации кислот при равновесном значении $\mathrm{pH}$. Второй показатель - обменная кислотность (Шамрикова, 2010), определяемая титрованием вытяжки до $\mathrm{pH} 8.2$ по методу А.В. Соколова, дополнительно учитывающая и более слабокислотные центры. Сопоставление этих двух показателей правомерно, так как используется одна и та же методика измерения (табл. 1). Равенство указанных показателей является особенностью изучаемых объектов, поскольку для большинства почв активность протонов, найденная по значениям $\mathrm{pH}_{\mathrm{KCl}}$, существенно ниже этого показателя, определенного титрованием.

Значительное содержание протонов в твердой фазе, способных к обмену с ионами калия, является, в том числе, следствием низкого количества ионов $\mathrm{Ca}^{2+}$ и $\mathrm{Mg}^{2+}$, способных нейтрализовать соединения кислой природы. Это подтверждает анализ элементного состава изучаемых объектов - массовая доля данных элементов в валовом составе не превышает $0.3 \%$ (табл. 1), что сопоставимо с результатами исследования химических свойств верхних слоев торфа олиготрофных участков болот таежной зоны Карелии (Елина, 1984). В подстилках автоморфных суглинистых почв тайги и тундры эти показатели выше на порядок и более и составляют соответственно $2-9$ и $1-2 \%$, значения $\mathrm{pH}_{\mathrm{KCl}}$ также существенно выше (Атлас почв..., 2010). Таким образом, одной из причин столь высокой кислотности изучаемых объектов может быть низкое содержание основных катионов, участвующих в нейтрализации соединений кислой природы.

Иными органическими соединениями, содержащими сильнокислотные группы, могут быть такие низкомолекулярные органические кислоты, как щавелевая $\left(\mathrm{p} K_{\mathrm{a} 1}=1.27\right)$, малеиновая $\left(\mathrm{p} K_{\mathrm{a} 1}=1.92\right)$, лимонная ( $\left.\mathrm{p} K_{\mathrm{a} 1}=3.06\right)$, а также наиболее сильнокислотные группы растворимых фульвокислот (ФК). В составе $Ф К$ методом $\mathrm{p} K$ спектроскопии выявлено наличие карбоксильных групп со значениями $\mathrm{p} K_{\mathrm{a}}=2.98$ (Лодыгин, 1999). При этом вопрос, насколько можно переносить результаты изучения препаратов $\Phi К$, выделенных из твердой фазы торфянисто-подзолисто-глееватой почвы при жесткой обработке, на высокомолекулярные соединения, переходящие в водную вытяжку из органогенных горизонтов, требует специального изучения.

Появление на поверхности высокомолекулярных соединений (BMC) сильнокислотных карбоксильных групп может быть отчасти связано с изменением их конформации при увеличении ионной силы раствора. Известно, что изменение формы является стадией, предшествующей высаливанию ВМС. Конформация соединений возникает и поддерживается за счет множества ионных и водородных связей, а также гидрофобных взаимодействий и определяет способность к отдаче протона функциональных групп кислот. Іредполагается, что молекула фульвокислоты гибкая, имеет вытянутую неправильную или червеобразную форму. Изменение ионной силы раствора вызывает разрыв одних слабых связей и образование других, что приводит к небольшим перемещениям отдельных участков цепи и появлению на поверхности новых, способных к ионизации функциональных групп, на что указывалось ранее (Davis, 1981; Sposito, 1977).

\section{Заключение}

На примере почв побережья Баренцева моря установлено, что повышение ионной силы раствора обеспечивает снижение эффективности экстракции общего углерода органических соединений объектов в 1.2 раза, низкомолекулярных кислот и углеводов, определенных методом ГХ/ MC - в среднем в 3 раза. Влияние морской воды в зоне подтопления может вызывать понижение мобильности органических соединений, особенно их низкомолекулярной фракции.

Предложено рассматривать отношение массовых концентраций растворимых низкомолекулярных углеводов к кислотам, определенных методом ГХ/МС, как интегральный индекс, отражающий совокупность биохимических свойств организмов, обуславливающих их способность обитать на данной территории, а также условия, определяющие пути трансформации органических остатков.

Работа выполнена в ралках телы государственного задания Института биологии Коли НЦ УрО РАН «Пространственно-временные закономерности форлирования торфяных почв на европейском северо-востоке России и их трансформации в условиях меняющегося клилата и антропогенного воздействия" (Гр. 115020910065$)$, а также проекта РФФИ № 16-34-00237 мол_а

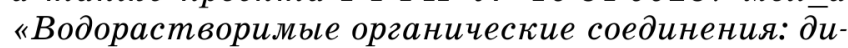
агностика совреленных процессов в почвах уязвимых экосистем (на примере арктических маршией)».

\section{ЛИТЕРАТУРА}

Артемкина, Н. А. Низкомолекулярные органические кислоты в почвенных водах лесов Кольско- 
го полуострова в условиях воздушного промышленного загрязнения / Н. А. Артемкина, Т. Т. Горбачева, Н. В. Лукина // Почвоведение. - 2011. - № 4. C. 21-29.

Атлас почв Республики Коми / Под ред. Г. В. Добровольского, А. И. Таскаева, И. В. Забоевой. Сыктывкар : КРТ, 2010. - 356 с.

Влияние разнообразия биоты на состав низкомолекулярных водорастворимых органических соединений почв южной тундры / Е. В. Шамрикова, О. С. Кубик, В. В. Пунегов, И. В. Груздев // Почвоведение. -2014 . - № 3. - C. 295-303. DOI: 10.7868/ S0032180X14030101.

Водорастворимые низкомолекулярные органические кислоты в автоморфных суглинистых почвах тундры и тайги / Е. В. Шамрикова, И. В. Груздев, В. В. Пунегов, Ф. М. Хабибуллина, О. С. Кубик // Почвоведение. - 2013. - № 6. - C. 691-697. DOI: 10.7868/S0032180X13060099.

Водорастворимые органические кислоты торфяных мерзлотных почв юго-востока Большеземельской тундры / Е. В. Шамрикова, Д. А. Каверин, А. В. Пастухов, Е. М. Лаптева, О. С. Кубик, В. В. Пунегов // Почвоведение. - 2015. - № 3. - С. 288295. DOI: 10.7868/S0032180X15030107.

ГОСТ Р 52991-2008. Вода. Методы определения содержания общего и растворенного органического углерода. - М : Изд-во стандартов, 2009. - 12 с.

Елина Г. А. Структурно-функциональная организация и динамика болотных экосистем Карелии / Г. А. Елина, О. Л. Кузнецов, А. И. Максимов. Л. : Наука, 1984. - 128 с.

Зеленский, О. В. Эколого-физиологические аспекты изучения фотосинтеза / О. В. Зеленский. Л. : Наука, 1977. С. 25-60.

Исследование водных вытяжек из подзолистых почв Республики Коми на содержание индивидуальных органических соединений / Е. В. Шамрикова, И. В. Груздев, В. В. Пунегов, Е. В. Ванчикова, А. А. Ветошкина // Почвоведение. - 2012. № $10 .-$ C. $1068-1076$.

Караванова, Е. И. Химический состав растворов макро- и микропор поверхностных горизонтов некоторых почв ЦЛГПБЗ / Е. И. Караванова, Е. А. Тимофеева // Почвоведение. - 2009. - № 12. C. 1456-1463.

Качественный анализ водных вытяжек из подзолистых почв Республики Коми на содержание органических соединений хромато-масс-спектроскопическим методом / Е. В. Шамрикова, И. В. Груздев, В. В. Пунегов, Е. В. Ванчикова, А. А. Ветошкина // Вода: химия и экология. -2011 . - № 11. C. 58-63.

Классификация и диагностика почв России / Авторы и составители: Л. Л. Шишов, В. Д. Тонко- ногов, И. И. Лебедев, М. И. Герасимова. - Смоленск : Ойкумена, 2004. - 342 с.

Лодыгин, Е. Д. Оценка кислотно-основных свойств торфянисто-подзолисто-глееватой почвы методом рК-спектроскопии / Е. Д. Лодыгин, Е. В. Шамрикова // Почва, экология, общество : тезисы докладов Докучаевских молодежных чтений. СПб., 1999. - С. 33.

Шамрикова, Е. В. Варьирование показателей кислотно-основного состояния автоморфных суглинистых почв таежной и тундровой зон Республики Коми / Е. В. Шамрикова, В. Г. Казаков, Т. А. Соколова // Почвоведение. - 2011. - № 6. - С. 699-712.

Шамрикова, Е. В. Кислотность КCl-вытяжек из органогенных горизонтов почв: источники, возможные равновесия / Е. В. Шамрикова // Почвоведение. - 2010. - № 7. - С. 811-818.

Юрцев, Б. А. Гипоарктический ботанико-географический пояс и происхождение его флоры / Б. А. Юрцев. - М. : Наука, 1966. - 94 с.

Clemente, J. S. Association of specific organic matter compounds in size fractions of soils under different environmental controls / J. S. Clemente, A. J. Simpson, M. J. Simpson // Organic Geochemistry. - 2011. - V. 42. - P. 1169-1180.

Davis, H. Titration of fulvic acid fractions II. Chemical changes at high pH / H. Davis, J. B. Mott // J. Soil Sci. - 1981. - V. 32. - P. 393-397.

Hamer, U. Priming effects in different soil types induced by fructose, alanine, oxalic acid and catechol additions / U. Hamer, , B. Marschner // Soil Biology \& Biochemistry. - 2005. - V. 37. - P. 445-454.

Liquid extraction of low molecular mass organic acid and hidroxamatesiderophores from boreal fotest soil / T. Ali, D. Bylund, S. Esen, U. Lundstrom // Soil Biology \& Biochemistry. - 2011. - V. 43. P. 2417-2422.

Sposito, G. Titration Studies on the Polynuclear Poliacidic Nature of Fulvic Acid Extracted from Sewage Sludge Soil Mixtures / G. Sposito, K. M. Holtsclaw // Soil Sci. Soc. Amer. Journal. - 1977. V. 41. - № 2. - P. 330-336.

Strobel, B. W. Influence of vegetation on lowmolecular-weight carboxylic acids in soil solution a review / B. W. Strobel // Geoderma. - 2001.

V. 99. - P. 169-198.

World Reference Base for Soil Resources. International soil classification system for naming soils and creating legends for soil maps: $3^{\text {rd }}$ ed. - Rome : FAO, 2014. - $203 \mathrm{p}$.

Wu, Y. Dissolved Organic Waters at Level II Monitoring Plots in Norway: Short- and Long-Term Variations / Y. Wu, N. Clarke, J. Mulder // Water Air Soil Pollut. - 2010. - V. 205. - P. 273-288.

\section{SOLUBLE ORGANIC COMPOUNDS OF PEAT SOILS OF THE NORTHERN PART OF THE BOLSHEZEMELSKAYA TUNDRA}

E.V. Shamrikova, S.V. Deneva, O.S. Kubik, V.V. Punegov, E.V. Kyzyurova, O.M. Zueva Institute of Biology of Komi Scientific Centre of the Ural Branch of the Russian Academy of Sciences, Syktyvkar

Abstract. Dissolved organic compounds of peaty soils of the Barents Sea coast were compared. Nine acids and seven carbohydrates were determined. Content of the total organic compounds carbon extracted by water varied in the range $0.1-0.5 \mathrm{~g} / \mathrm{dm}^{3}$, low-molecular carbohydrates $-1-24$, acids $-6 \mathrm{mg} / \mathrm{dm}^{3}$. The mass fraction of carbon of the identified compounds was less than $4 \%$ of the total organic carbon of the extracts.

Key words: peat soils, the Arctic, water and $\mathrm{KCl}$-extracts from soils, low-molecular organic acids and carbohydrates 